\title{
The Academic Medicine Handbook
}

\author{
Laura Weiss Roberts (Ed.): The Academic Medicine Handbook: A Guide to Achievement \\ and Fulfillment for Academic Faculty. Springer, New York, NY, 2013, 978-1-4614-5693-3, \\ 486 pages; $\$ 69.95$ (softcover); $\$ 49.95$ (eBook)
}

\author{
Steven L. Dubovsky
}

Received: 2 April 2014 / Accepted: 24 April 2014 / Published online: 20 May 2014

(C) Academic Psychiatry 2014

Does your medical school department have a formal orientation and mentoring program for new faculty? If so, you might want to look at this book for hints about topics to include. If not, a glance at this book might inspire you to start one.

This multiauthored book covers just about every topic a new faculty member would want to know about, from finding a position, to writing case reports or designing studies, to getting promoted, to balancing personal and professional activities. Each chapter ends with a summary of "words to the wise," and suggestions of things to "ask your mentor or colleagues." Some chapters also contain "key concepts" or summaries of complex issues covered in the chapters. Most chapters are mercifully concise, making it possible to scan the material quickly or read it a little more carefully.

As might be expected in any large, edited volume, there is some inconsistency of style and of detail, with interesting variability in whether the wording is in the first or third person. Chapters on understanding different faculty tracks and formulating case reports have universal appeal, while a chapter on understanding flaws in clinical research is very useful but presented in considerably more detail than the rest of the book. A number of chapters repeat material that can be found in any faculty handbook, but they at least remind the reader to find such a handbook and read it. As a demonstration of how to maximize publication credit, one four-page chapter is authored by two people and has a one-half page appendix by a third author. A few chapters just about reach the level of polemic and will mainly be of interest to readers who expect to feel devalued professionally.

A good thing about the variability of the material in this book is that there will be something for just about everyone. The book will be useful as a resource for individuals starting a career in academic medicine and probably for senior residents who are considering such a career. Although not every faculty member will want to buy it, having it available in a departmental, school, or hospital library as a resource would be a benefit to the junior faculty.

Disclosures The author has no conflicts of interest.

S. L. Dubovsky $(\triangle)$

e-mail: dubovsky@buffalo.edu 